\title{
Härkäpapu kanojen rehuna
}

Erja Koivunen ${ }^{1}$, Jarmo Valaja ${ }^{1}$, Petra Tuunainen ${ }^{1}$ ja Eija Valkonen ${ }^{2}$

${ }^{1}$ MTT, Kotieläintuotannontutkimus, 31600 Jokioinen, Suomi, etunimi.sukunimi@mtt.fi

${ }^{2}$ Hankkija-Maatalous Oy, 05801 Hyvinkää, Suomi, etunimi.sukunimi@agrimarket.fi

\section{Tiivistelmä}

Valkuaistuotannon omavaraisuutta pyritään lisäämään soijan rajoittuneen saatavuuden ja suurten hintavaihteluiden takia. Härkäpapu (Vicia faba L.) on soijarouheelle vaihtoehtoinen kotimainen valkuaisen lähde, joka sopii suuren lysiinipitoisuutensa vuoksi, hyvin täydentämään viljapohjaista rehua. Härkäpapua viljelemällä voidaan vähentää typpilannoitteiden käyttöä. Härkäpavun käyttöä eläinten rehuna rajoittavat useat haitta-aineet kuten visiini ja konvisiini. Visiinin ja konvisiinin on todettu aiheuttavan anemiaoireita ihmiselle ja ne voivat aiheuttaa niitä myös siipikarjalle.

Tämän tutkimuksen tavoitteena oli määrittää kotimaisen härkäpapulajike Konnun siementen käyttömäärä munivien kanojen dieetissä. Tutkimuksessa oli kaksi koetta. Ensimmäisessä kokeessa tutkittiin härkäpavun vaikutusta kanojen kuolleisuuteen. Kokeessa oli 640 LSK-kanaa, neljä ruokintaryhmää ja 40 ruokintakerranetta. Kokeen alkaessa kanat olivat 29 viikon ikäisiä. Kokeessa härkäpavun käyttömäärät olivat toisen kokeen käyttömääriä huomattavasti suuremmat ja soijarouhetta korvattiin härkäpavulla $0,33,67$ ja $100 \%$. Koe päätettiin neljän ensimmäisen viikon jälkeen kanojen suuren kuolleisuuden takia ja kokeen osalta vain kumulatiiviset kuolleisuusprosentit on raportoitu.

Toisessa kokeessa oli 560 LSK-kanaa. Kanojen ikä kokeen alussa oli 39 viikkoa. Ruokintaryhmiä oli viisi ja ruokintakerranteita 35. Jokaista ruokintaryhmää kohden oli 7 ruokintakerrannetta. Kokeessa viljapohjaisten rehujen päävalkuaislähde oli soijarouhe. Kontrollidieettinä oli tavanomainen munivien kanojen dieetti ilman härkäpapua. Neljä härkäpapudieettiä sisälsi joko prosessoimatonta (myöhemmin raaka härkäpapu) tai prosessoitua härkäpapu $5 \%$ tai $10 \%$. Härkäpapu prosessoitiin jauhamalla vasaramyllyllä, expanderkäsittelemällä ja rakeistamalla. Koe kesti 40 viikkoa ja kokeessa oli 10 neljän viikon tuotannonseurantajaksoa. Kanojen rehu vaihtui viiden ensimmäisen tuotannonseurantajakson jälkeen. Ruokintaryhmien rehut optimoitiin energia-, raakavalkuias-, aminohappo-, kivennäis- ja vitaminiinipitoisuuksiltaan samanlaisiksi.

Ensimmäisessä kokeen patologisissa tutkimuksissa kanojen kuolinsyyksi todettiin aplastinen anemia, joka todennäköisesti aiheutui härkäpavun visiinistä ja konvisiinistä. Toisessa kokeessa härkäpavun prosessointi vähensi härkäpavun visiinin ja konvisiinin yhteenlaskettua pitoisuutta hyvin vähän (raaka härkäpapu $10,6 \mathrm{~g} / \mathrm{kg} \mathrm{ka}$ ja prosessoitu härkäpapu $8,9 \mathrm{~g} / \mathrm{kg} \mathrm{ka}$ ). Härkäpapurehuilla ruokkiminen ei vaikuttanut tuotantoon $(\mathrm{g} / \mathrm{vrk} / \mathrm{kana})$, mutta härkäpapurehuja syövät kanat munivat kevyempiä munia kuin kontrolliryhmän kanat. Tuotanto väheni ja rehunmuuntosuhde (rehua/muna-kg) suureni härkäpavun määrän lisääntyessä (5 \% vs. 10 \%). Härkäpavun prosessoinnilla ei ollut vaikutusta tuotantotuloksiin. Kanojen kuolleisuus lisääntyi lähes merkitsevästi härkäpapurehuja syötettäessä. Tämän tutkimuksen perusteella sekä raakaa että prosessoitua härkäpapua voidaan käyttää vähintään $5 \%$ munivien kanojen dieetissä ilman, että tuotanto heikkenee tai kuolleisuus lisääntyy.

Asiasanat: härkäpapu; kana; munien tuotanto; terveys 


\section{Johdanto}

Valkuaistuotannon omavaraisuutta pyritään lisäämään soijan rajoittuneen saatavuuden ja suurten hintavaihteluiden takia. Härkäpapu (Vicia faba L.) on soijarouheelle vaihtoehtoinen kotimainen valkuaisen lähde, joka sopii suuren lysiinipitoisuutensa vuoksi, hyvin täydentämään viljapohjaista rehua. Härkäpavulla on kyky sitoa ja palauttaa maahan maaperäntyppeä, mikä tekee siitä ympäristön suojelun kannalta hyvin arvokkaan viljelykasvin (Duc 2007). Härkäpavun käyttöä eläinten rehuna rajoittavat kuitenkin useat haitta-aineet kuten valkuaisen sulavuutta heikentävät tanniinit ja proteaasi-inhibiittorit sekä suurina määrinä myrkylliset lektiini, visiini ja konvisiini. Visiinin ja konvisiinin on todettu aiheuttavan anemiaoireita ihmiselle ja ne voivat aiheuttaa niitä myös siipikarjalle. Tutkimuksen tavoitteena oli selvittää, miten härkäpapu soveltuu kanojen valkuaisrehuiksi ja selvittää kuinka paljon kotimaista härkäpapulajiketta Kontua voidaan käyttää munivien kanojen dieetissä.

\section{Aineisto ja menetelmät}

Tutkimuksissa oli kaksi koetta. Kanat olivat molemmissa kokeissa Triotecin virikehäkeissä. Yhdessä häkissä oli kahdeksan kanaa ja kaksi häkkiä muodosti yhden ruokintakerranteen. Ensimmäisessä kokeessa (koe 1) oli 640 LSL-kanaa, joiden ikä kokeen alussa oli 24 viikkoa. Ruokintakerranteita oli 40. Ruokintaryhmää kohden oli kymmenen kerrannetta. Kokeessa oli neljä ruokintaryhmää. Kontrolliryhmä sai tavanomaista viljapohjaista rehua, jonka ainut valkuaisrehu oli soijarouhe (ruokintaryhmä 1). Muiden ruokintaryhmien dieeteissä soijarouhetta korvattiin raa`alla härkäpavulla 33, 67 ja $100 \%$ (ruokintaryhmät 2, 3 ja 4). Ruokintaryhmien 3 ja 4 kanat siirtyivät pois koedieeteiltä suuren kuolleisuuden takia kesken ensimmäisen tuotannonseurantajakson (neljä ensimmäistä viikkoa) ja koe päätettiin ensimmäisen tuotannonseurantajakson jälkeen. Kokeesta on tuloksia vain tältä jaksolta ja vain kumulatiiviset kuolleisuusprosentit on raportoitu.

Toisessa kokeessa (koe 2) oli 560 LSK-kanaa. Kanojen ikä kokeen alussa oli 39 viikkoa. Kokeessa ruokintaryhmiä oli viisi. Jokaista ruokintaryhmää kohden oli seitsemän ruokintakerrannetta, jolloin ruokintakerranteita oli yhteensä 35. Kontrolliryhmän (ruokintaryhmä 6) dieettinä oli tavanomainen viljapohjainen rehu, jonka ainut valkuaisrehu oli soijarouhe. Neljä härkäpapudieettiä sisälsi joko raakaa tai prosessoitua härkäpapu $5 \%$ tai $10 \%$ (ruokintaryhmät 7,8 ja 9). Kokeessa oli kymmenen neljän viikon jaksoa. Koerehujen koostumusta muutettiin viiden jakson (20 viikon) jälkeen kokeen aloittamisesta. Ruokintaryhmien rehut optimoitiin energia-, raakavalkuais-, aminohappo-, kivennäis- ja vitamiinipitoisuuksiltaan samanlaisiksi.

Härkäpapu prosessoitiin jauhamalla vasaramyllyllä, expanderkäsittelemällä $\left(90-110{ }^{\circ} \mathrm{C}, 5-20\right.$ bar, valmennus $70-80{ }^{\circ} \mathrm{C}$ ) ja rakeistamalla 3,5 millimetrin rakeeksi. Koe rehut sisälsivät ohraa, vehnää, kauraa, soijarouhetta, härkäpapua, rypsiöljyä sekä tarvittavia kivennäis- ja hivenaineita, vitamiineja sekä puhtaita aminohappoja. Koerehut höyryrakeistettiin 4 millimetrin seulalla. Koerehujen raaka-aineista (ohra, vehnä, kaura, soijarouhe ja härkäpavut) ja koerehuista määritettiin kuiva-aine ja tehtiin rehuanalyysi. Kaikki rehuanalyysit tehtiin yhdistetyistä näytteistä.

Kanat punnittiin kokeen alussa, puolivälissä ja kokeen lopussa. Munien laatumääritys (kuoren kestävyys, kuoren paksuus, ominaispaino, Haugh-luku) tehtiin kaksi kertaa kokeen aikana kahdeksasta munasta joka kerranteesta (neljännen ja kahdeksannen jakson aikana). Munat lähetettiin pakkaamolle käsittelyryhmittäin, jotta saatiin ryhmien keskimääräinen pakkaamolaatu. 


\section{Tulokset ja niiden tarkastelu}

Kokeen 1 ruokintaryhmien kanoista kuoli ensimmäisten neljän viikon aikana $0 \%, 3,75 \%$, $31,86 \%$ ja 37,50 \% (ruokintaryhmät1, 2,3 ja 4). Kumulatiiviset kuolleisuusprosentit on laskettu vain ensimmäisen jakson osalta. Ryhmät kolme ja neljä siirtyivät pois koedieeteiltä kesken ensimmäisen jakson. Patologisissa tutkimuksissa kuolinsyyksi todettiin aplastinen anemia, jonka todennäköisesti aiheutti härkäpavun visiini ja konvisiini.

Koerehujen valmistusaineet on esitetty taulukoissa 1 (koe 1) ja 2 (koe 2). Kokeen 2 rehujen laskennalliset rehuarvot ja rehujen kemiallinen koostumus on esitetty taulukossa 3. Prosessointi vähensi härkäpavun visiinin ja konvisiinin pitoisuutta hyvin vähän. Tämän kokeen härkäpavussa oli melko paljon visiiniä ja konvisiiniä. Ra``a härkäpavun visiinin ja konvisiinin yhteenlaskettupitoisuus oli 10,6 g/kg ka ja kypsennetyn 8,9 g/kg ka. Tavanomaisesti raa `an härkäpavun visiinin ja konvisiinin yhteenlaskettupitoisuus on $6-14 \mathrm{~g} / \mathrm{kg} \mathrm{ka}$ ja pitoisuus ei yleensä vähene prosessoinnin aikana. (Crépon ym. 2010).

Härkäpavun prosessointi vähensi hieman munintaprosenttia $5 \%$ :n käyttötasolla ja lisäsi sitä 10 $\%: n$ käyttötasolla, jolloin härkäpavun prosessoinnin ja käyttömäärän välillä oli suuntaa antava yhdysvaikutus munintaprosenttiin $(\mathrm{p}<0,01)$. Munien paino pieneni kontrolliin verrattuna härkäpapurehuja käytettäessä ( $\mathrm{p}<0,05)$. Myös Davidson ym. (1973) ja Crépon ym. (2010) totesivat tutkimuksessaan, että munien paino pienenee härkäpapua käytettäessä. Härkäpavun kypsennyksen ja käyttömäärän välillä havaittiin yhdysvaikutus $(\mathrm{p}<0,05)$. Härkäpavun kypsennys suurensi munien painoa $5 \%$ :n käyttötasolla, mutta pienensi sitä $10 \%$ :n käyttötasolla. (Taulukot 4 a ja b).

Munan tuotanto (g/pv/kana) väheni ja rehunmuuntosuhde (rehua kg/muna-kg) heikkeni härkäpavun osuuden lisääntyessä dieetissä (tuotanto: $p<0,01$, rehunmuuntosuhde: $p<0,05$ ). Näyttäisi siltä, että härkäpavun osuus dieetissä voi olla ainakin $5 \%$ ilman, että tuotanto vähenee ja rehunmuuntosuhde heikkenee. Tulos on yhtenäinen Créponin ym. (2010) tutkimustuloksen kanssa, jonka mukaan härkäpavun osuus dieetissä voi olla enintään $7 \%$ ilman että tuotantotulokset heikkenevät. Käytettäessä härkäpapulajikkeita, joissa on vähän visiiniä ja konvisiiniä, härkäpavun osuus dieetissä voi olla jopa $20 \%$ (Crépon ym. 2010). Fru-Njin ym (2007) mukaan härkäpapurehuilla ruokittaessa tuotannon heikkeneminen voi johtua visiinistä ja konvisiinista, mutta myös välttämättömien aminohappojen puutteesta. Tässä tutkimuksessa tuotannon väheneminen johtui todennäköisesti visiinistä ja konvisiinistä, koska rehujen aminohappopitoisuudet optimoitiin samanlaisiksi. Ruokintaryhmien rehunkulutukset (g/pv/kana) eivät eronneet toisistaan.

Kuolleisuus lisääntyi suuntaa antavasti kontrolliin verrattuna härkäpapurehuja käytettäessä (p<0,01). Ruokintaryhmien 7,8 ja 9 kuolleisuudet olivat suurempia kuin kontrolliryhmän kuolleisuus, mutta kontrolliryhmän kuolleisuus oli ryhmän 6 kuolleisuutta suurempi. Tämä todennäköisesti selittää vain suuntaa antavan merkitsevyyden. (Taulukot 4 a ja b). Kokeen 1 jälkeen kanat saattoivat jakautua sattumalta kokeen 2 ruokintaryhmiin niin, että kokeen 1 härkäpapuruokinnoilla oli yhteys kokeen 2 kuolleisuuksiin.

Munien laatu (ominaispaino, kuorenkestävyys, Haugh-luku, kuoren paksuus) ei eronnut ruokintaryhmien välillä (Tukeyn testi). Kontrolliryhmä ja ruokintaryhmä, jonka dieetti sisälsi $5 \%$ raakaa härkäpapua, munivat hieman enemmän kuin muut ryhmät ja ryhmien munista tilitettiin hieman enemmän kuin muiden ruokintaryhmien munista. Kontrolliryhmä muni enemmän XL- ja Lkokoisia munia kuin muut ruokintaryhmät. Muut ruokintaryhmät munivat puolestaan enemmän Mkokoisia munia. Tulos on yhtenäinen Gréponin ym. (2010) tuloksen kanssa, jonka mukaan härkäpavulla ei ole vaikutusta munien laatuun, mutta munien koon ja dieetin härkäpapuosuuden välillä on negatiivinen korrelaatio. Kanojen painot eivät eronneet ruokintaryhmien välillä kokeen alussa, puolivälissä ja lopussa. 


\section{Johtopäätökset}

Tämän tutkimuksen perusteella härkäpavun prosessointi ei merkittävästi vähennä visiinin ja konvisiinin yhteenlaskettua pitoisuutta. Härkäpavun prosessoinnilla ei tämän kokeen perusteella ole vaikutuksia tuotantotuloksiin tai vaikutukset ilmenevät epäselvinä kypsennyksen ja härkäpavun käyttömäärän välisinä yhdysvaikutuksina. Härkäpapurehuilla ruokittaessa munien laatu ei huonone, mutta munien koko voi hieman pienentyä. Käytettäessä suuria härkäpapu määriä linnut voivat altistua aplastiselle anemialle, joka todennäköisesti johtuu visiinistä ja konvisiinistä. Tämän tutkimuksen perusteella härkäpavun osuus munivien kanojen dieetissä voi olla vähintään $5 \%$ ilman, että tuotantotulokset heikkenevät ja kuolleisuus lisääntyy soijarouheruokintaan verrattuna.

Taulukko 1. Kokeen 1 koerehujen valmistusaineet $(\mathrm{g} / \mathrm{kg})$.

\begin{tabular}{lcccc}
\hline & \multicolumn{4}{c}{ Ruokintaryhmä } \\
Valmistusaineet & 1 & 2 & 3 & 4 \\
\hline Ohra & 249,6 & 223,9 & 198,9 & 173,7 \\
Vehnä & 214,0 & 193,0 & 171,5 & 150,0 \\
Kaura & 214,0 & 193,0 & 171,5 & 150,0 \\
Soijarouhe & 179,6 & 119,8 & 59,9 & 0,0 \\
Härkäpapu, raaka & 00,0 & 123,4 & 247,1 & 371,0 \\
Rypsiöljy & 24,7 & $2,8,2$ & 31,6 & 35,2 \\
Monokalsiumfosfaatti & 14,5 & 14,5 & 14,4 & 14,3 \\
Ruokintakalkki & 92,0 & 92,0 & 92,2 & 92,4 \\
Ruokasuola & 4,0 & 4,0 & 4,0 & 04,0 \\
Kana-Hiven & 2,0 & 2,0 & 2,0 & 02,0 \\
Kana-vita & 3,7 & 3,7 & 03,7 & 03,7 \\
Metioniini & 1,34 & 1,68 & 2,04 & 2,40 \\
Lysiini & 0,53 & 0,36 & 0,18 & 0,00 \\
Treoniini & 0,00 & 0,33 & 0,65 & 0,96 \\
Tryptofaani & 0,00 & 0,14 & 0,26 & 0,39 \\
\hline
\end{tabular}

1 = Kontrolli, 2 = Härkäpavulla korvattu $33 \%$ soijarouheesta, 3 = Härkäpavulla korvattu $66 \%$ soijarouheesta, 4 = Härkäpavulla korvattu $100 \%$ soijarouheesta 
Taulukko 2. Kokeen 2 koerehujen valmistusaineet (g/kg).

Kontrolli

Valmistusaineet

Ohra

Vehnä

Kaura

Soijarouhe

Härkäpapu, raaka

Härkäpapu, kypsä

Rypsiöljy

Monokalsiumfosfaatti

Poikaskalkki

Ruokasuola

Kana-Hiven

Kana-vita

Metioniin

Lysiini

Treoniini

214,0

0,0

24,0

93,8

4,0

2,0

3,7

1,34

0,36

0,00
Raaka härkäpapu

$\begin{array}{lll} & 5 \%\end{array}$

$214,0 \quad 227,0$

227,0

205,5

205,5

205,5
145,8

50,0

40,0

0,0

25,5

0,0

12,0

$14,5 \quad 14,0$
95,5

4,0

2,0

3,7

1,00

0,17

0,00
14,5

93,8

4,0

2,0

3,7

1,48

0,27

0,13

263,3

116,1

50,0

0,0

13,2

14,0

95,5

4,0

2,0

3,7

1,15

0,11

0,13

\section{Ruokintaryhmä}

7

8

9

Prosessoitu härkäpapu härkäpapu Prosessoitu härkäpapu

$263,3 \quad 247,8$

247,8

205,5

205,5

145,8

263,3
218,4
218,
116,
0,0
50,0
13,2
14,0
95,5
4,0
2,0
3,7
1,15
0,11
0,13
$10 \%$

237,7
196,7

196,7

252,7

252,7

\section{9,5}

196,7

100,0

0,0
26,8

14,5

93,8

4,0

2,0

3,7

1,63

0,20

0,25

0,13

0,13

0,25

92,6

100,0

0,0

14,9

14,0

95,5

4,0

2,0

3,7

1,30

0,00

0,26 $10 \%$

\begin{tabular}{cc}
\multicolumn{2}{c}{$10 \%$} \\
237,7 & 252,7 \\
196,7 & 209,5
\end{tabular}

$196,7 \quad 209,5$

$122,1 \quad 92,6$

$0,0 \quad 0,0$
0,0

100,0

100,0

$26,8 \quad 14,9$

$14,5 \quad 14,0$

$\begin{array}{ll}14,5 & 14,0 \\ 93,8 & 95,5\end{array}$

$4,0 \quad 4,0$

$2,0 \quad 2,0$

$\begin{array}{ll}3,7 & 3,7\end{array}$

$1,63 \quad 1,30$

$\begin{array}{ll}1,63 & 1,30 \\ 0,20 & 0,00\end{array}$

0,25

0,26


Taulukko 3. Kokeen 2 keskimääräiset koerehujen laskennalliset rehuarvot ja kemiallinen koostumus ( $\mathrm{g} / \mathrm{kg}$ ka ellei toisin mainita).

\begin{tabular}{|c|c|c|c|c|c|}
\hline & \multicolumn{5}{|c|}{ Käsittely } \\
\hline & 5 & 6 & 7 & 8 & 9 \\
\hline & Kontrolli & Raaka & Prosessoitu & Raaka & Prosessoitu \\
\hline & & härkäpapu & härkäpapu & härkäpapu & härkäpapu \\
\hline & & & & $10 \%$ & $10 \%$ \\
\hline \multicolumn{6}{|l|}{$\begin{array}{l}\text { Laskennalliset } \\
\text { rehuarvot }\end{array}$} \\
\hline $\mathrm{ME}(\mathrm{MJ} / \mathrm{kg})$ & 10,60 & 10,60 & 10,60 & 10,60 & 10,60 \\
\hline Raakavalkuainen & 153,92 & 153,91 & 153,91 & 152,74 & 153,93 \\
\hline Metioniini & 3,60 & 3,60 & 3,60 & 3,61 & 3,61 \\
\hline Lysiini & 7,27 & 7,27 & 7,27 & 7,27 & 7,27 \\
\hline Treoniini & 5,50 & 5,65 & 5,50 & 5,50 & 5,50 \\
\hline \multicolumn{6}{|l|}{$\begin{array}{l}\text { Kemiallinen } \\
\text { koostumus }\end{array}$} \\
\hline Kuiva-aine (g/kg) & 902,8 & 907,6 & 909,7 & 907,8 & 907,9 \\
\hline Tuhka & 141,45 & 139,85 & 145,70 & 143,55 & 145,70 \\
\hline Raakavalkuainen & 160,15 & 158,70 & 157,40 & 159,55 & 158,90 \\
\hline Raakarasva & 48,70 & 53,20 & 52,55 & 53,35 & 53,70 \\
\hline Raakakuitu & 48,40 & 45,80 & 46,10 & 56,00 & 51,60 \\
\hline Typettömät uuteaineet & 611,70 & 616,15 & 597,70 & 587,35 & 563,35 \\
\hline
\end{tabular}


Taulukko 4 a. Rehun härkäpapupitoisuuden ja härkäpavun prosessoinnin vaikutus munivien kanojen tuotantotuloksiin kokeessa 2.

\begin{tabular}{lcccccc}
\hline & & \multicolumn{3}{c}{ Ruokintaryhmä } & & \\
& 5 & 6 & 7 & 8 & 9 & \\
& Kontrolli & $\begin{array}{c}\text { Raaka } \\
\text { härkäpapu } \\
5 \%\end{array}$ & $\begin{array}{c}\text { Prosessoitu } \\
\text { härkäpapu } \\
5 \%\end{array}$ & $\begin{array}{c}\text { Raaka } \\
\text { härkäpapu } \\
10 \%\end{array}$ & $\begin{array}{c}\text { Prosessoitu } \\
\text { härkäpapu } \\
10 \%\end{array}$ & SEM \\
\hline $\begin{array}{l}\text { Munintaprosentti } \\
\text { Munan paino, g }\end{array}$ & 90,0 & 91,4 & 90,9 & 88,0 & 90,9 & 0,85 \\
$\begin{array}{l}\text { Tuotanto, } \\
\text { g/pv/kana }\end{array}$ & 66,1 & 64,6 & 65,7 & 65,1 & 64,3 & 0,46 \\
$\begin{array}{l}\text { Rehunkulutus, } \\
\text { g/pv/kana }\end{array}$ & 59,5 & 59,0 & 59,7 & 57,2 & 58,4 & 0,55 \\
$\begin{array}{l}\text { Rehunkulutus, } \\
\text { kg/muna-kg }\end{array}$ & 114,5 & 114,3 & 116,9 & 122,4 & 116,6 & 3,03 \\
Kuolleisuus $1, \%$ & 1,93 & 1,94 & 1,97 & 2,14 & 2,00 & 0,053 \\
\hline
\end{tabular}

${ }^{1}$ Kumulatiivinen kuolleisuus, SEM = keskiarvon keskivirhe.

Taulukko 4 b. Kontrastien p-arvot.

\begin{tabular}{|c|c|c|c|c|}
\hline & $\mathrm{C} 1$ & $\mathrm{C} 2$ & C3 & $\mathrm{C} 2 \times \mathrm{C} 3$ \\
\hline Munintaprosentti & & & $\mathrm{O}$ & $\mathrm{O}$ \\
\hline Munan paino, g & $*$ & & & $*$ \\
\hline Tuotanto, g/pv/kana & & & $* *$ & \\
\hline $\begin{array}{l}\text { Rehunkulutus, } \\
\text { g/pv/kana }\end{array}$ & & & & \\
\hline $\begin{array}{l}\text { Rehun muuntosuhde, } \\
\mathrm{kg} \text { rehua/muna-kg }\end{array}$ & & & * & \\
\hline Kuolleisuus, \% & $\mathrm{o}$ & & & \\
\hline $\begin{array}{l}{ }^{1} \text { Kumulatiivinen kuol } \\
\text { C2: rehussa raakaa hä } \\
\text { C3: rehussa } 5 \% \text { härk } \\
* * *(\mathrm{P}<0,001), * *(\mathrm{P}<0\end{array}$ & $\begin{array}{l}\text { us, C } \\
\text { ipua } \\
\text { la vs } \\
* \text { (D }\end{array}$ & $\begin{array}{l}\text { troll } \\
\text { uussa } \\
\text { sa } 10 \\
\text { ja o }\end{array}$ & $\begin{array}{l}\text { ärkä } \\
\text { irkäj } \\
\text { apu }\end{array}$ & \\
\hline
\end{tabular}

\section{Kirjallisuus}

G. Duc. 2007. Faba bean (Vicia faba L.). Field. Crop. Res. 53:99 - 109.

J. Davidson. 1973. The nutritive value of field beans (Vicia faba L.) for laying hens. Br. Poult. Sci. 14:557 - 567.

F. Fru-Nji, E. Niess, E. Preffer. 2007. Effect of Graded Replacement of Soybean Meal by Faba Beans (Vicia faba L.) or Field Peas (Pisum sativum L.) in Rations for Laying Hens on Egg production and quality. J. Poult. Sci. 44:34-41.

K. Grépon, P. Marget, C. Peyronnet, B. Carrouée \& G. Duc, G. 2010. Nutritional value of faba bean (Vicia faba L.) seeds for feed and food. Field. Crop. Res. 115: 329-339. 